\title{
New Generation of Smart Highway: Framework and Insights
}

\author{
Chenglong Liu $\mathbb{D},{ }^{1,2}$ Yuchuan Du $\left(\mathbb{D},{ }^{1,2}\right.$ Yiheng Ge $\mathbb{D}^{2},{ }^{2}$ Difei Wu $\mathbb{D}^{1},{ }^{1}$ Cong Zhao $\mathbb{D}{ }^{1}$ \\ and Yishun $\mathrm{Li} \mathbb{D}^{1}$ \\ ${ }^{1}$ The Key Laboratory of Road and Traffic Engineering, Ministry of Education, Tongji University, Shanghai 201804, China \\ ${ }^{2}$ Shanghai Engineering Research Center of Urban Infrastructure Renewal, Shanghai 200032, China
}

Correspondence should be addressed to Yuchuan Du; ycdu@tongji.edu.cn

Received 17 September 2021; Revised 13 October 2021; Accepted 2 November 2021; Published 16 December 2021

Academic Editor: Linchuan Yang

Copyright (C) 2021 Chenglong Liu et al. This is an open access article distributed under the Creative Commons Attribution License, which permits unrestricted use, distribution, and reproduction in any medium, provided the original work is properly cited.

\begin{abstract}
The new generation of smart highway (NGSH) has become an irresistible global trend to improve transport efficiency and safety. The exploration of the features and framework for NGSH can guide us to upgrade the current highway system. This paper summarizes the fundamental features of the NGSH from the perspective of the interactive evolution of automobile industry and road transport. In line with the popularity of automated and connected vehicles, the primary technical features of the NGSH are proposed as (I) complete elements sensing, (II) cyber-physical systems, (III) cooperative vehicle-infrastructure applications, and (IV) 5th generation mobile communication technology. The corresponding physical framework and data flow are introduced, in which three data attributes (data accuracy, dimensionality, and freshness) are highlighted to describe the data requirements for various scenarios. The development path of the NGSH is further discussed in terms of the different vehicle automation levels. The characteristics of five levels of NGSH are identified from R1 to R5. Different combinations of NGSH level and vehicle automation level lead to distinct system functions. Several urgent problems in the current stage are pointed out in terms of system compatibility, standard specification, and information security. This paper provides new insights for sustainable and reproducible highway reformation, drawing some implications for NGSH design.
\end{abstract}

\section{Introduction}

Highway is a fundamental component of the road transport system, which connects major cities along its route crossing all provinces and reaching nearly all of their capital cities [1]. It is a strong support for national economics. The highway in China has reached over 150,000 km in 2020, ranking first in the world [2]. With the rapid growth of highway's coverage, how to use advanced sensing, computing, and communication technologies to improve its service capability has been a pivotal issue for the next generation of smart highway (NGSH). China's fastpaced development has resulted in it being one of the most flexible nations in terms of technological integration into the NGSH [3]. In 2014, the Ministry of Transport of China released the "Four Transportation" strategy and proposed the concept of "smart transportation" [4]. In the following years, the conception of smart transportation has constantly been enriched and refined, generating many new technical forms, such as smart highway, smart pavement, and smart infrastructures [5]. Various regions and cities in China, such as Zhejiang, Shanghai, and Shandong, have carried out a large number of exploratory pilot projects to construct the smart highway system and achieve fruitful results. However, some of them are case-specific and function-oriented, making them quite hard to be replicated in other areas. The framework of the NGSH directly affects its portability and effectiveness, which is also of considerable significance to the evolution of the current road transport system.

The concept of the smart highway was proposed internationally as early as the 1940s [6]. In 1992, the United States launched the Automated Highway System (AHS) program and built a vehicle-vehicle $(\mathrm{V} 2 \mathrm{~V})$ and vehicle-infrastructure (V2I) communication module to reduce traffic congestion and improve driving safety [7]. In the early 21 st century, the Smart Highway project in Virginia was an important milestone for intelligent transportation system in America. It integrated multiple technologies such as facility performance monitoring, energy recovery, and automated driving to create 
a 2.2-mile smart expressway [8]. The smart corridor is one of the most representative smart highway programs in the US conducted on the I-80 highway in California [9]. This system integrated a variety of sensing and active transportation technologies through electronic identification and dedicated short-range communication (DSRC) to improve driving safety and transit time reliability [10]. Since the 1990s, Japan has carried out many research and projects of intelligent transportation systems [11]. The SmartWay public test released in 2006 has become a worldwide ITS benchmark. The system contains vehicle information and communication system (VICS), electronic toll collection system (ETC), advanced safety vehicle system (ASV), and other functional modules to improve the user's travel experience [12]. Tokyo Motor Show 2015 exhibited the ETC 2.0 that takes V2I as the core to enhance tolling collection and information exchange between vehicles and facilities [13]. Japan has formed unified standards throughout the country and employed ETC and VICS systems. In the middle of the last century, Europe started the research on smart road infrastructure, which is mainly oriented by sustainability, eco-transport and safety, including the famous "Euraka" plan [14] and EasyWay project [15]. In 2013, Drive Me, a Gothenburg experimental road, provided roadside sensing data to vehicles in real-time for functions such as automatic parking and adaptive cruise [16]. In 2016, Norway's E8 highway applied vehicle-road collaboration to create a unique scenario application for autonomous truck driving [17]. Most countries utilized roadside cameras, millimeter-wave radars, etc. to achieve a large-scale perception of the road environment and combined different communication methods for information interaction between vehicles and infrastructures. The objectives vary from automated driving, accident alert, eco-based driving, safety enhancement, etc. Table 1 compares the technical features of typical smart highway projects throughout the world.

China built multiple smart highways for automated/ semiautomated driving and cooperative vehicle-infrastructure systems (CVIS). For example, Zhejiang integrates technologies such as free-flow charging, wireless charging, and partially automated driving to create a "Superhighway" of 161 kilometers. Its driving speed is expected to exceed 120 kilometers per hour $[18,19]$. Hunan builds 113 kilometers of " $5 \mathrm{G}+$ " smart highway to achieve precise sensing of each section of the road and each vehicle to create a dynamic digital high-definition map for L3-L5 automated driving [20]. Based on the BeiDou Navigation Satellite System (BDS), Guangxi province constructs a smart highway system with functions of vehicle guidance, safety monitoring, and digitization of facilities for drivers. Shandong province launched the first domestic fully autonomous smart highway, which uses advanced laser radars, microwave radars, and other technologies to conduct macro-control of vehicles [20]. This program can significantly improve traffic efficiency and safety for fully connected automated vehicles, but the testing can only be applied at the designated training ground in the current stage instead of open environment. Although China has made tremendous achievements in the construction of smart highways, it has not yet produced a unified and instructive definition and framework of the
NGSH. The lack of unified standards and design has affected the large-scale promotion of the NGSH nationwide.

As a new type of technical form of the road transport, the NGSH will become a reliable measure to solve traffic congestion and road crashes. The clarity of its fundamental architecture can effectively guide the design of the NGSH and serve as a complement to the current transportation system. The remainder of this paper is organized as follows: section 2 presents the interactive development between the automobile industry and road transport, which derives the connotation of the NGSH; section 3 elaborates the corresponding technical framework from the perspectives of physical architecture and data attributes; section 4 describes its development path and defines different levels of the NGSH; finally, conclusion part presents the findings of this study.

\section{Understandings of the New Generation of Smart Highway}

2.1. Technical Features of the NGSH. The core function of the road is the carrier of road users. According to the evolution history of the road transport system (see Figure 1), it shows an interactive development trend with the automobile industry. The first electric vehicle was invented in 1881, marking that the automobile has become a new tool for human mobility [21]. The Benz Patent-Motorwagen, built in 1885, is widely regarded as the world's first oil-fueled automobile, which is propelled by an internal combustion engine. Since then, the automobiles have gradually realized volume production [22]. However, the inadequate performance of road facilities has limited the efficiency of the vehicles. Therefore, the tarmac roads generated in 1901 provided a solid foundation for the development of automotive technology, leading to an improvement of vehicles' driving speed [23]. With the rapid expansion of human's social and travel distances, the automobiles require a safer and more efficient driving environment. There comes the highway system, which has the dedicated right-of-way and confined driving space. The world's first highway was built in 1932, and then it was widely adopted internationally [24]. Since the 21st century, the automated driving and Internet of vehicles have put forward new requirements for the existing highway system. The interactions between vehicles and roads are strengthened, leading the previous "weak tie" connection to become the "strong tie" coupling. The information exchange between them has been an indispensable part in the next generation of a road transport system. Therefore, the technical features of the NGSH need to fully consider the development status and functional requirements of the automotive industry.

User demand is the primary driving force for upgrading the highway system. At the beginning of the 20th century, hardening the pavement is the most significant measure to improve the serviceability of the pavement. By hardening the pavement, the traffic capacity of a single-lane increased to $600-800 \mathrm{pcu} / \mathrm{h}$, and the driving speed can reach up to $40-60 \mathrm{~km} / \mathrm{h}$ [25]. As the economic activities vigorously grew, the scope of people's activities was further expanded, producing lots of city-to-city travel demand. Therefore, the engineers came up with an "exclusive" highway system in 
TABLE 1: Typical smart highway projects and technical features.

\begin{tabular}{|c|c|c|c|c|}
\hline Area & Project & Communication & Key functions & Technical features \\
\hline \multirow{3}{*}{ US } & AHS [7] & DSRC & $\begin{array}{c}\text { Collision avoidance } \\
\text { Dynamic navigation } \\
\text { Vehicle auxiliary control }\end{array}$ & $\begin{array}{l}\text { V2V/V2I communication } \\
\text { Automated roadside system }\end{array}$ \\
\hline & Virginia smart road [8] & $\begin{array}{l}\text { High-bandwidth fiber } \\
\text { network }\end{array}$ & $\begin{array}{l}\text { Energy recovery } \\
\text { Pavement perception } \\
\text { Intelligent lighting }\end{array}$ & $\begin{array}{l}\text { Smart infrastructures } \\
\text { Centralized } \\
\text { communications }\end{array}$ \\
\hline & I-80 SMART [9] & Optical cable & $\begin{array}{c}\text { Adaptive ramp control } \\
\text { Dynamic event broadcast } \\
\text { Bus priority driving }\end{array}$ & $\begin{array}{l}\text { Real-time traffic } \\
\text { information } \\
\text { Electronic signs, ramp } \\
\text { meters }\end{array}$ \\
\hline Japan & SmartWay [12] & DSRC & $\begin{array}{c}\text { ETC } \\
\text { Traffic broadcast } \\
\text { Route optimization } \\
\text { Over-the-horizon sight }\end{array}$ & $\begin{array}{c}\text { Roadside sensor network } \\
\text { ITS-on-board-unit } \\
\text { VICS }\end{array}$ \\
\hline \multirow{3}{*}{ Europe } & E8-aurora [17] & $\mathrm{C}-\mathrm{V} 2 \mathrm{X}$ & $\begin{array}{c}\text { Mobility as a service } \\
\text { Automated driving in extreme } \\
\text { weathers }\end{array}$ & $\begin{array}{l}\text { Digital road facilities } \\
\text { Intelligent asset } \\
\text { management }\end{array}$ \\
\hline & E8- borealis [17] & $\mathrm{C}-\mathrm{V} 2 \mathrm{X}$ & Truck autopilot & $\begin{array}{l}\text { Digital road facilities } \\
\text { C-ITS, V2V, V2I, V2X } \\
\text { Radar and camera fusion }\end{array}$ \\
\hline & Goteborg drive me [16] & $\mathrm{C}-\mathrm{V} 2 \mathrm{X}$ & $\begin{array}{l}\text { Automated driving } \\
\text { Automated parking }\end{array}$ & $\begin{array}{c}\text { Internet of vehicles } \\
\text { Infrastructure specifications } \\
\text { Sensus navigation }\end{array}$ \\
\hline \multirow{2}{*}{ China } & $\begin{array}{c}\text { Smart highway, Shandong } \\
{[18]}\end{array}$ & $\begin{array}{c}5 \mathrm{G} \\
\text { LTE-V }\end{array}$ & $\begin{array}{l}\text { Automated driving } \\
\text { Truck platoon } \\
\text { Full-element awareness }\end{array}$ & $\begin{array}{l}\text { Semi-closed test field } \\
\text { High precision positioning } \\
\text { Internet of things } \\
\text { Fiber grating }\end{array}$ \\
\hline & $\begin{array}{c}\text { Super highway, Zhejiang } \\
{[19]}\end{array}$ & $\begin{array}{l}5 \mathrm{G} \\
\text { LTE-V } \\
\text { DSRC }\end{array}$ & $\begin{array}{l}\text { Free-flow tolling system } \\
\text { Wireless charging } \\
\text { Automated driving } \\
\text { Data-driven maintenance }\end{array}$ & $\begin{array}{l}\text { Energy recovery pavement } \\
\text { Cloud \& edge computing } \\
\text { High precision positioning } \\
\text { 5G-based VIIF system }\end{array}$ \\
\hline
\end{tabular}

*AHS: automated highway system; DSRC: dedicated short-range communications; V2V: vehicle-to-vehicle; V2I: vehicle-to-infrastructure; V2X: vehicle-toeverything; ETC: electronic toll collection system; VICS: vehicle information and communication system; C-V2X: cellular vehicle-to-everything; C-ITS: cooperative intelligent transport systems; LTE-V: long-term evolution-vehicle; 5G: 5th generation mobile network; VIIF: vehicle and infrastructure information fusion.

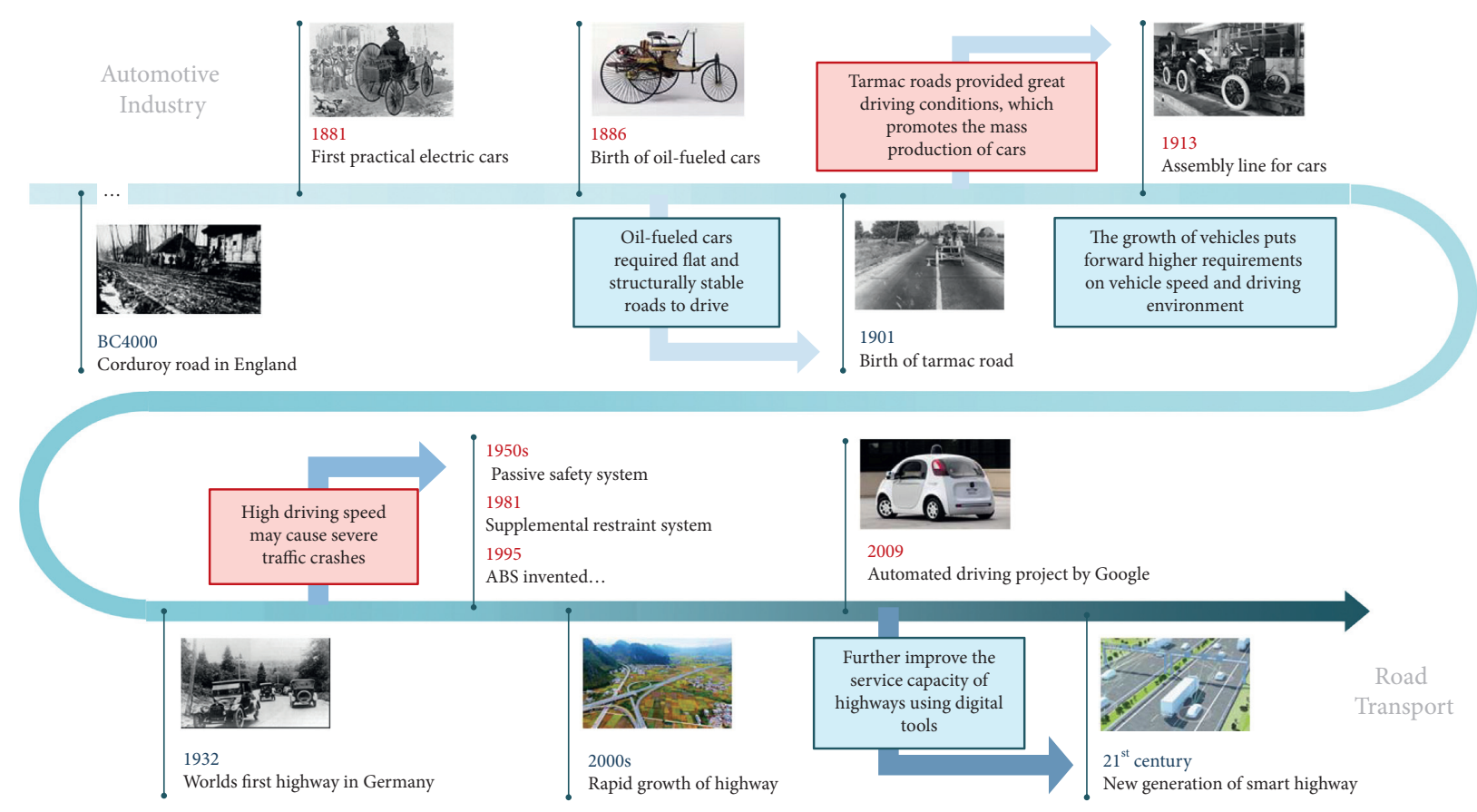

FIGURE 1: Interactive development of automobile industry and road transport. 
1932, which only serves as a way open for the use of motor vehicles. The highway system expanded the single-lane capacity to $1800-2400 \mathrm{pcu} / \mathrm{h}$ and raised the vehicle speed to $80-120 \mathrm{~km} / \mathrm{h}$ [26]. Given the gradual saturation of land resources, there are limited lands to construct new roads. The precise and fast sensing technology and low-latency communication assist vehicles in reducing their headway distance and ensure the stability of vehicle control under the existing infrastructure conditions. According to the simulation and field tests, the traffic capacity can leap up to $3000-3500 \mathrm{pcu} / \mathrm{h}$, and the driving speed would exceed $120 \mathrm{~km} / \mathrm{h}$ [27]. The basic idea of the NGSH is to combine the multiple, distributed, and precise sensing, computation, and communication technologies to improve the highway's capacity and driving speed, which also serves digital infrastructure management and safety enhancement (see Figure 2).

2.2. Fundamental Components of the NGSH System. The application of NGSH varies in terms of road users and managers. For users, the service functions are designed towards different automation levels of vehicles. As for L2 or less, the NGSH mainly provides reliable environmental information and corresponding service support, such as free-flow charging, hazard weather warning, and route and speed guidance [28]. For semiautomated driving vehicles (L3 L4), the NGSH utilizes its advantages of large-scale integrated sensing to enhance the vehicles' perception and provides more dedicated information to ensure driving safety. For fully automated vehicles (L5), the NGSH controls the vehicle fleet and platooning from the macro-perspective to improve the efficiency of the whole highway, as illustrated in Figure 3.

For managers, the NGSH monitors the status of static facilities and dynamic vehicles in real-time to carry out lifecycle maintenance management and optimization, which improves the response capabilities of emergencies and guarantees the stability of system operation. Based on the above requirements, the components of NGSH are roughly divided into four categories: (I) complete elements sensing, (II) cyber-physical systems (CPS), (III) cooperative vehicle-infrastructure applications, and (IV) high-speed communication (see Figure 4).

Complete elements sensing mainly applies advanced distributed sensing technologies such as video, millimeterwave radar, and high-precision positioning system to achieve full element awareness of transportation system, which serves as the underlying structure of the NGSH. For example, vehicle reidentification, trajectory reconstruction, and velocity detection are applied to describe dynamic objects. Distress detection, roughness perception, marking recognition, etc. are employed to evaluate the quasistatic objects, such as pavement and roadside facilities. Environmental information such as hazard weather, water accumulation, and poor visibility is also recorded with a short interval. The NGSH fuses and correlates all these sensing data to construct a dynamic complete element sensing network.

Cyber physical system (CPS) is a computer system, in which a mechanism is controlled or monitored by computer-based algorithms [29]. CPS is similar to the digital twin platform [30], which reflects the dynamic operation information of the elements throughout their life cycle, and can spatially represent the sensing data through the global identification tags and data fusion model. CPS has the characteristics of the Internet of Things (IoT), but the CPS presents a higher combination and coordination between physical and computational elements [31]. The CPS platform is a living digital simulation that brings all the sensing data together and updates it from multiple sources to depict its physical counterpart dynamically. The CPS is the core platform of the NGSH.

CVIS applications refer to the use of complete sensing data and CPS platform to realize the application of automated driving and lifecycle infrastructure management, including CVIS-based fully automated driving, vehicle platooning control, sustainable maintenance scheduling, and rapid emergency response. According to different development stages of the NGSH, the systematic applications may vary from a single module to multiple superimposed functions.

Communication media refers to the use of 5G, DSRC, $\mathrm{C}-\mathrm{V} 2 \mathrm{X}$, and other communication techniques to transfer data flow among the smart highway system's core components. The $5 \mathrm{G}$ communication is expected to be a suitable tool for the large-scale vehicle-to-road information exchange [32], leading to the real-time calculation and processing of the integrated sensing data. In turn, the fused results and control orders from CPS platform can be sent to the vehicles by $5 \mathrm{G}$ in real-time.

\section{Technical Framework of the New Generation of Smart Highway}

The technical framework of the NGSH is designed based on its physical entities and types of application. The former explains the basic elements, physical composition, data mode, and information flow of the NGSH system. The latter enumerates the application scenarios.

3.1. Basic Elements of the NGSH. The first step to develop the technical framework of the NGSH is to determine its basic elements. Current studies prefer to determine the basic elements based on the application scenarios or the type of information. However, such definitions are not appropriate for the top-level framework design of the NGSH due to the complex items and function in the NGSH system. Thus, this study adopted a new method for determining the basic elements of the NGSH from the aspect of data freshness. Through summarizing the data requirements of each application scenario in the NGSH, the basic elements of the NGSH are determined as the four types of elements: highly dynamic elements, transient dynamic elements, transient static elements, and permanent static elements, as shown in Figure 5.

(1) Highly dynamic elements mainly include different types of traffic states, including the vehicles, roadblock, trajectories, and control commands.

(2) Transient dynamic elements mainly include the road network conditions, including the work zones, traffic congestions, weather conditions, road toll information, and signal control information. 


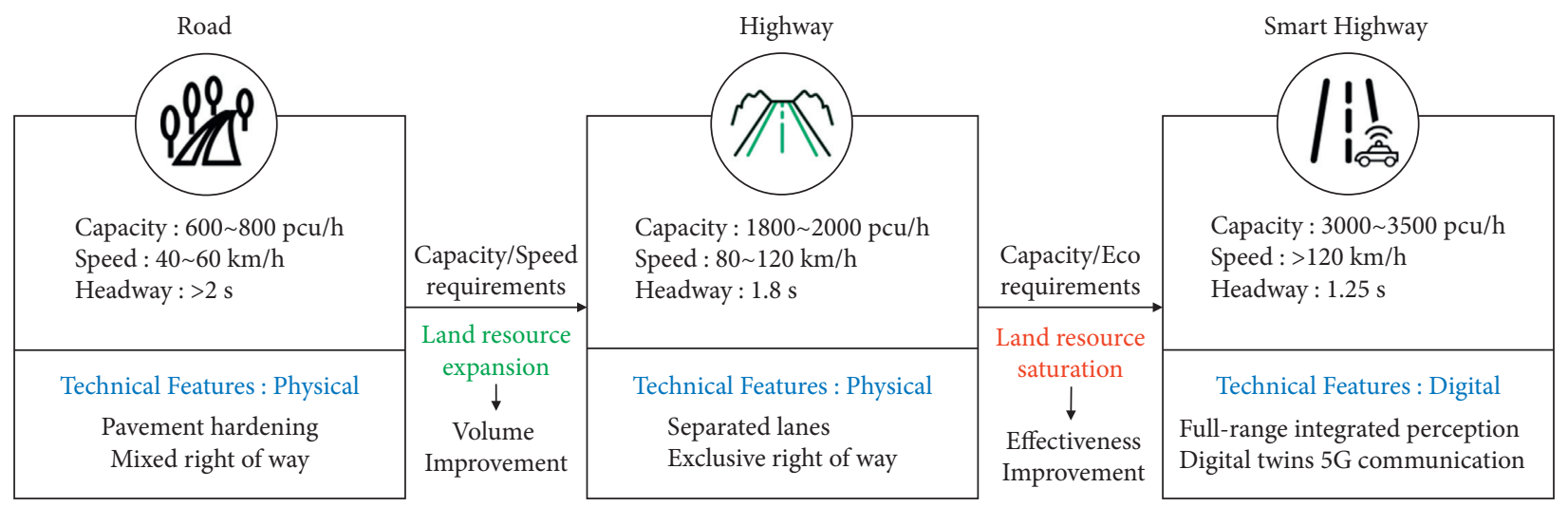

FIgURE 2: Process of upgrading the technical form of the road transport system.

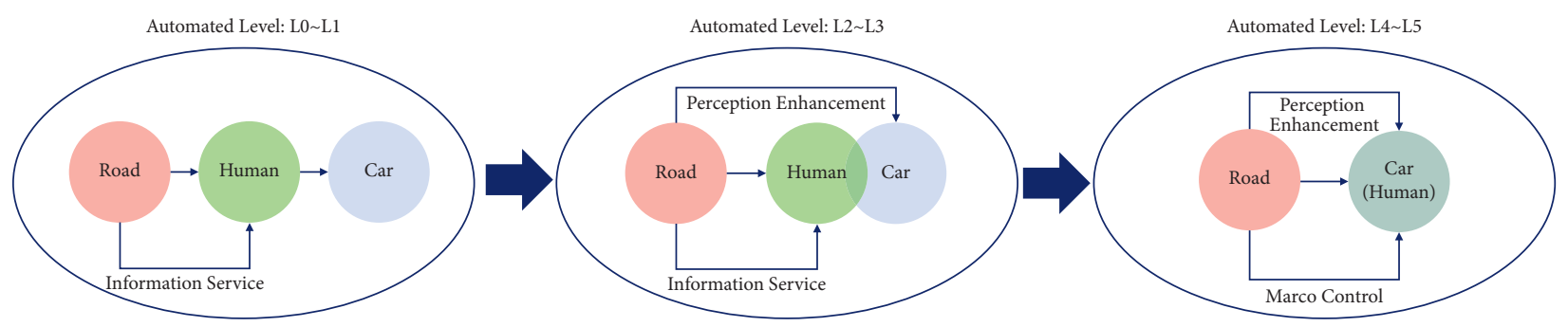

Figure 3: Functions of NGSH for different level of automation.

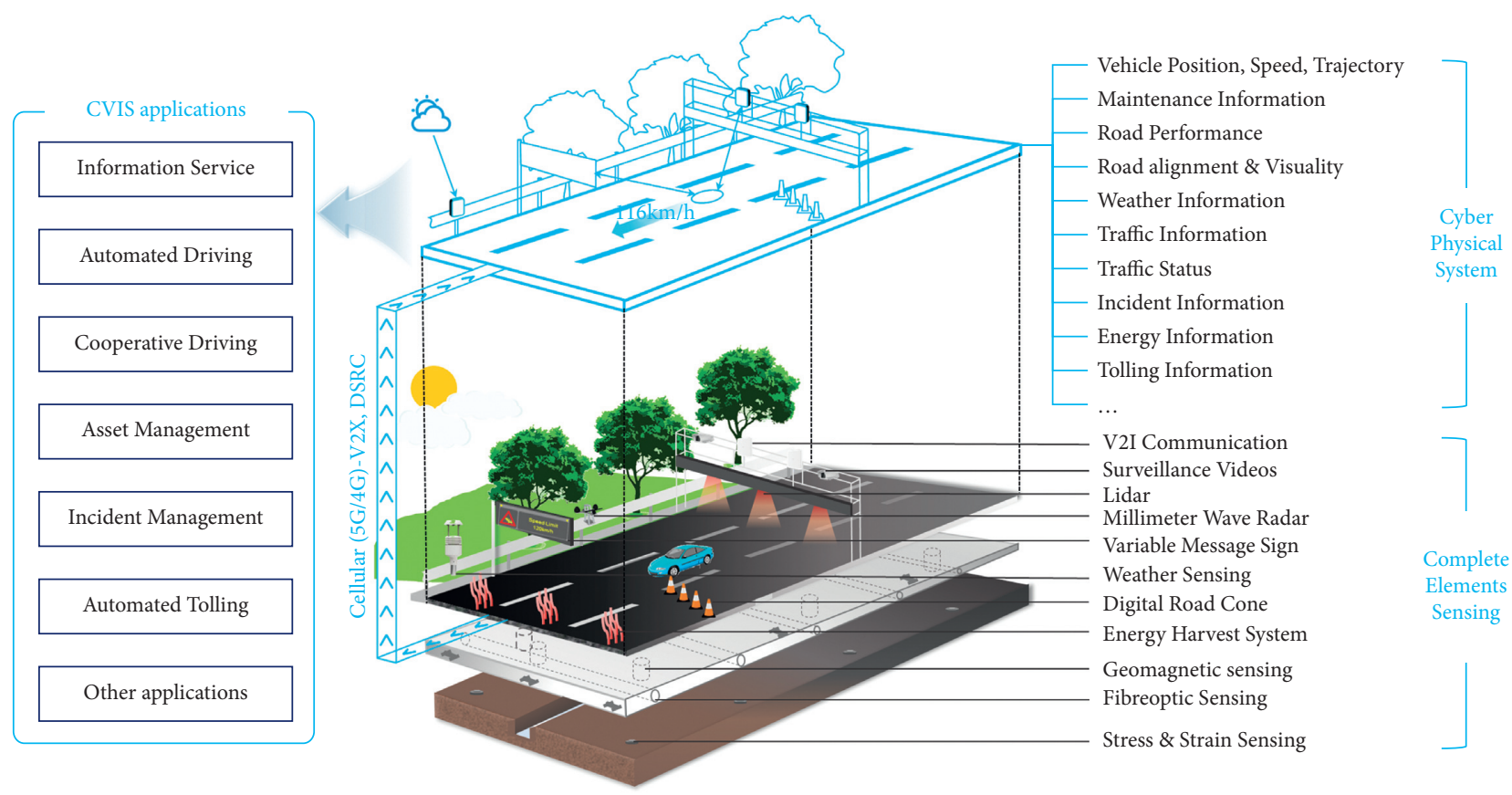

Figure 4: Main components of NGSH. 


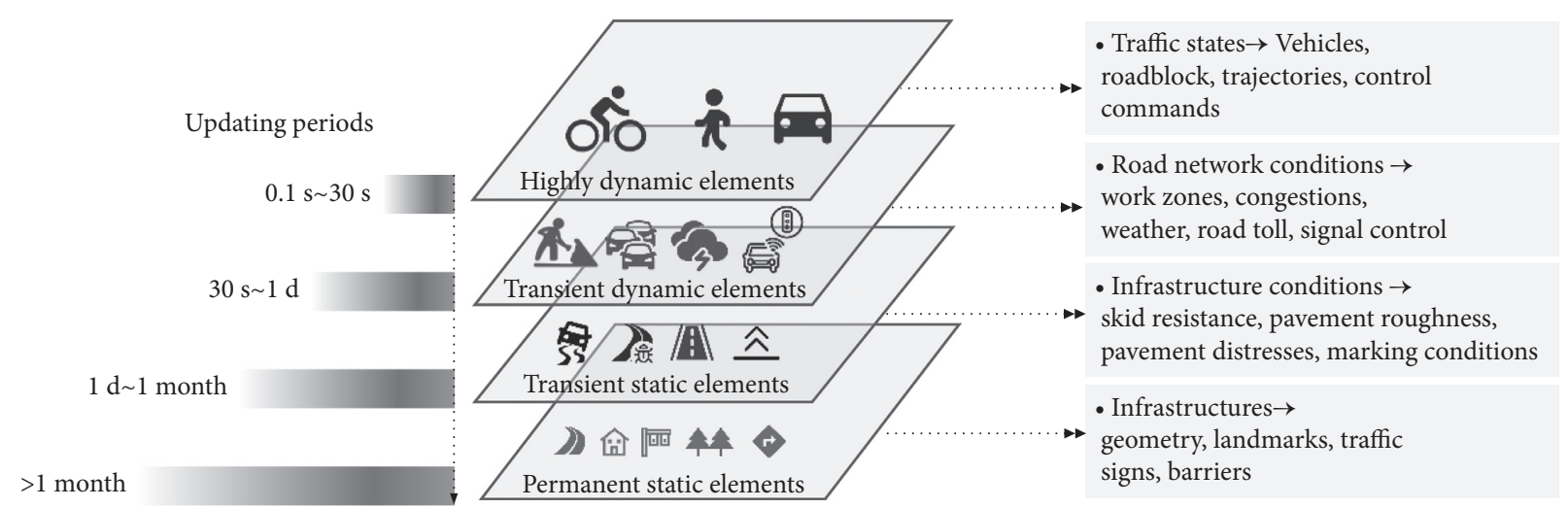

FIGURE 5: Basic elements of NGSH.

(3) Transient static elements are mainly the road network infrastructure conditions, including the pavement skid resistance, pavement roughness and unevenness, pavement distresses, and marking conditions.

(4) Permanents static elements refer to the features that are stable and almost unchanging, including the road geometry, landmarks, traffic signs, and barriers.

3.2. Physical Architecture of the NGSH. Architecture of an intelligent system can be developed by two methods: objectoriented method and process-oriented method. Compared with process-oriented method, object-oriented method focuses mainly on the objects in the system, with few characterizations on the process between objects, which is more scalable, reusable, and adaptable. Thus, this study adopts the object-oriented method to develop the physical architecture of the NGSH.

Figure 6 illustrates the physical architecture of the NGSH. The four objects of the architecture are firstly determined based on the basic elements. The attribute information, the perception methods, the processing, and analyzing methods are encapsulated in the element determinations and then make up the perception layer. For each object, different perception methods are adopted for data collection and information gathering.

The perceived data are then uploaded to the CPS layer by means of emerging communication techniques such as the $5 \mathrm{G}$ communication. The CPS platform is composed of the physical elements including the database, the basic platform, the computation center, and the functional platform. The CPS platform relies on the high-resolution digital base map. The physical elements of NGSH are mapped and managed in the CPS platform. The basic database is the management center of the massive multisource heterogeneous data such as digital infrastructure information, operational conditions, and environment data, the core of which is to ensure the synchronization of the data in physical and virtual worlds. Various types of data are presented in the basic platform according to data protocol. The computation center contains multiple virtual models, decision models, and analysis models, providing sufficient data resources to support the application systems.
The top layer of NGSH architecture is the application systems, which contains multiple services including the CVIS, intelligent infrastructure management and maintenance, information service, and intelligent traffic management. Compared to the other two layers, the architecture of the application system is more flexible and can be constituted by one or several functions.

The foundation of the physical framework is the complete sensing network and CPS management platform. The two parts must be compatible and replicable, which is conducive to promoting the productization and commercialization of the NGSH. It is also noted that the operation of one single application may require multiple information from CPS layer and perception layer. For instance, the automated vehicle in the CVIS requires both road geometry information (permanent static object), skid resistance information (transient static object), signal control information (transient dynamic object), and surrounding vehicle information (highly dynamic object) for data fusion and processing to generate control strategies.

3.3. The Data Requirements of the NGSH. The physical architecture defines the basic elements and major components in the NGSH system. For different application scenarios or systems, the data requirements are distinct. They must be specified firstly, because they determine the selection of perception method and the technical requirements of the perception devices. Therefore, we discuss the data requirements from the aspects of data dimension and accuracy, referring to the data richness and data precision. Table 2 summarizes the data requirements corresponding to different application scenarios.

3.4. Application Architecture of the NGSH. From the perspective of the applications, the users in NGSH involve private vehicles, commercial vehicles, traffic operation authorities and asset management departments, etc. Figure 7 describes the applications for multiple types of users. Private drivers can efficiently capture the data including the traffic condition, infrastructure status, and environment conditions to improve their driving safety and efficiency [33]. For commercial driving, the vehicles can be controlled remotely 


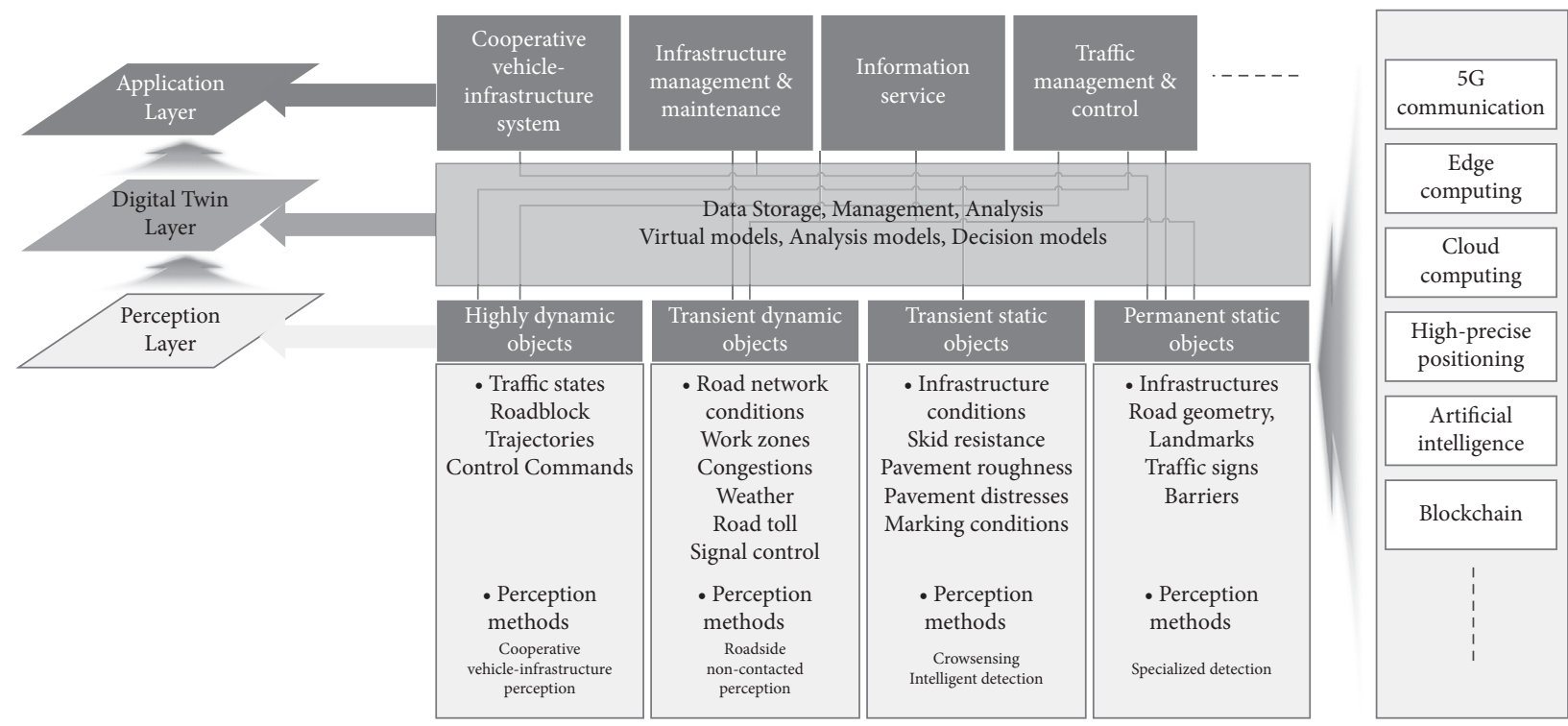

Figure 6: Physical architecture of the NGSH.

TABLE 2: Data requirements of the NGSH for different applications.

\begin{tabular}{|c|c|c|c|c|c|c|c|c|}
\hline \multirow{2}{*}{$\begin{array}{l}\text { Applications } \\
\text { CVIS }\end{array}$} & \multicolumn{2}{|c|}{ Highly dynamic data } & \multicolumn{2}{|c|}{$\begin{array}{c}\text { Transient dynamic } \\
\text { data }\end{array}$} & \multicolumn{2}{|c|}{ Transient static data } & \multicolumn{2}{|c|}{$\begin{array}{l}\text { Permanent static } \\
\text { data }\end{array}$} \\
\hline & $\begin{array}{c}\text { Accuracy } \\
\text { Dimension }\end{array}$ & $\begin{array}{l}00000 \\
00000\end{array}$ & $\begin{array}{c}\text { Accuracy } \\
\text { Dimension }\end{array}$ & $\begin{array}{l}00000 \\
00000\end{array}$ & $\begin{array}{c}\text { Accuracy } \\
\text { Dimension }\end{array}$ & $\begin{array}{c}0000 \\
000\end{array}$ & $\begin{array}{c}\text { Accuracy } \\
\text { Dimension }\end{array}$ & $\begin{array}{c}000 \\
00\end{array}$ \\
\hline Asset management \& maintenance & $\begin{array}{c}\text { Accuracy } \\
\text { Dimension } \\
\end{array}$ & 0 & $\begin{array}{c}\text { Accuracy } \\
\text { Dimension }\end{array}$ & $\begin{array}{l}000 \\
000\end{array}$ & $\begin{array}{c}\text { Accuracy } \\
\text { Dimension } \\
\end{array}$ & $\begin{array}{c}000 \\
00000\end{array}$ & $\begin{array}{c}\text { Accuracy } \\
\text { Dimension }\end{array}$ & $\begin{array}{l}000 \\
000\end{array}$ \\
\hline Information service & $\begin{array}{c}\text { Accuracy } \\
\text { Dimension }\end{array}$ & $\begin{array}{l}00000 \\
00000\end{array}$ & $\begin{array}{c}\text { Accuracy } \\
\text { Dimension }\end{array}$ & $\begin{array}{l}0000 \\
0000\end{array}$ & $\begin{array}{c}\text { Accuracy } \\
\text { Dimension }\end{array}$ & $\begin{array}{l}000 \\
000\end{array}$ & $\begin{array}{c}\text { Accuracy } \\
\text { Dimension }\end{array}$ & $\begin{array}{l}0 \bullet \\
\bullet\end{array}$ \\
\hline Traffic management \& control & $\begin{array}{c}\text { Accuracy } \\
\text { Dimension }\end{array}$ & $\begin{array}{l}0000 \\
00000\end{array}$ & $\begin{array}{c}\text { Accuracy } \\
\text { Dimension }\end{array}$ & $\begin{array}{c}000 \\
000\end{array}$ & $\begin{array}{c}\text { Accuracy } \\
\text { Dimension }\end{array}$ & 00 & $\begin{array}{c}\text { Accuracy } \\
\text { Dimension }\end{array}$ & ๑๐ \\
\hline
\end{tabular}

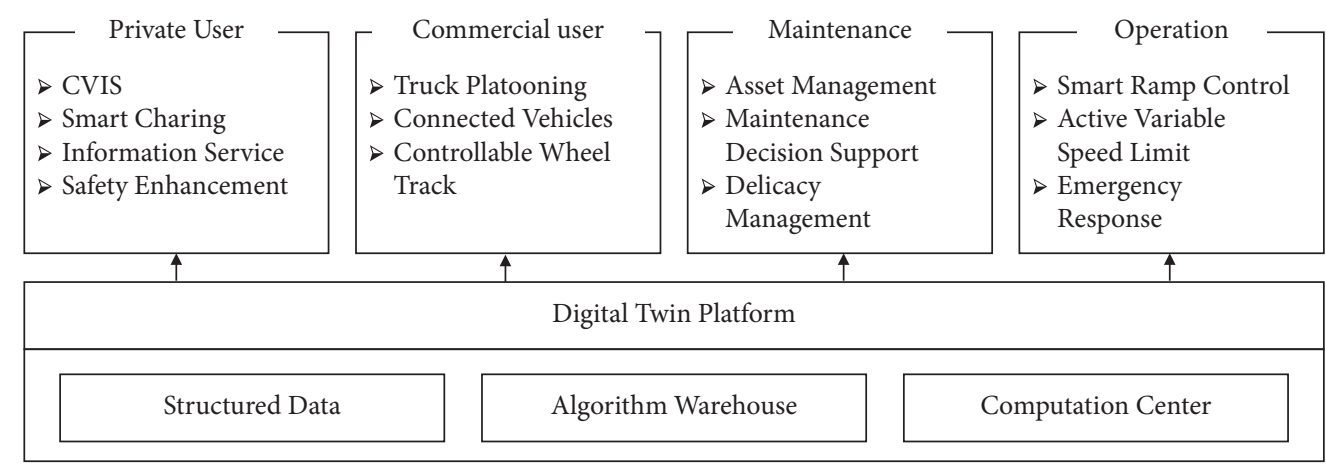

FIgURE 7: Applications architecture of the NGSH. 
to achieve the automated driving and vehicle platooning based on the real-time traffic and environment data. Based on the infrastructure and traffic operation data, the NGSH empowered the ability of the intelligent asset management and lifecycle maintenance.

\section{Development Path of New Generation of Smart Highway}

4.1. Interactive Development of NGSH and Automated Vehicles. The development of NGSH is a process of mutual promotion of intelligent vehicles and smart roads, which needs to be built together with the emerging technologies. The effectiveness depends on both the vehicle's automation level and the highway's smart level.

Similar to the classification of automation level of automated vehicles (AVs), NGSH can also be divided into different smart levels according to their digital abilities. Carreras et al. established a road infrastructure support levels for AVs (ISA levels) [34]. These levels can be assigned to parts of the network in order to give AVs guidance for the coming highway automation era. The core idea about this classification scheme is to differentiate the infrastructure considering their digital functions, such as digital information, cooperative perception, and cooperative driving. The NGSH as a whole is composed of many smart infrastructures. The NGSH serves not only AVs, but also traffic operators. Therefore, the smart levels of NGSH are determined by both their data features and support functions, as shown in Table 3. Five smart levels are defined from conventional highway (road smart level 1, R1) to fully smart highway (road smart level 5, R5). The details of data attributes can refer to Table 2, and the function attributes are roughly categorized into three aspects according to ISA levels.

From the user's perspective, the combination of the vehicles and highways with different automated and smart levels can realize diverse functions, as shown in Figure 8. Without vehicle-to-road communication, even the highestlevel roads cannot provide information services for L0 vehicles. However, for L5 AVs, they can achieve autonomous driving without any external infrastructure support, so they can be applied on R1 R5 highways. Similarly, cooperative driving cannot take effect without highly dynamic data. For R4 roads and L4 vehicles, vehicles perceive most the dynamic data under normal conditions, and roads can provide auxiliary sensing data of regions of interest. They achieve the complete elements awareness together, making cooperative driving possible. With the upgrade of NGSH, smart infrastructures of the highway will provide vehicles with stronger perception capabilities, empowering them with the functions of high-level autonomous driving. In some scenarios, the combinations of different levels of AVs and NGSH achieve a similar effect. For example, both 'L4 vehicles + R3 highway' and 'L2 vehicles + R5 highway' can reach autonomous driving. Therefore, the smart level of the NGSH should be rationally designed according to the automation level of the major operating vehicles in practice.
From the operator's perspective, different smart levels of NGSH improve operational capabilities to varying degrees. We concentrate on three major tasks (asset management, safety enhancement, and efficiency improvement) for identifying the effectiveness of different levels of NGSH (see Figure 9). For low-smart level highways, most operation works are conducted manually, which are time-consuming and labor-intensive. For highways with highly smart level, data can be collected with distributed sensors, and tasks can be completed by automated equipment. As most operation works do not need to know the highly dynamic data of each moving vehicle, R4 and R5 highways basically have the same functions. With the increase of the smart level of NGSH, significant economic and environmental benefits will also be generated. By reducing delay time, improving traffic efficiency, and optimizing vehicle trajectory, pollution emissions, and fuel consumption can be effectively reduced. The classification method proposed in this paper is mainly oriented to the smart and digitalization level of highways. A detailed discussion of its economic and environmental impact will be carried out in future work.

4.2. Key Issues in Current Stage for Developing NGSH. The NGSH reshapes the existing highway system by using digital and intelligent technology to improve its serviceability, such as traffic capacity, driving speed, and driving safety. The NGSH explores the potential of the current physical facilities. However, there are still many critical issues in practice, which are summarized as follows:

(1) At present, some NGSH functions are too "ahead of the time," resulting in poor compatibility with the current system. For example, some scenarios are dedicatedly designed for L4/L5 AVs. However, considering the limitations of laws and regulations, highways can only be used for the testing of autonomous driving. The deployment of too many roadside facilities for AVs hardly brings out the value of the NGSH at this stage. It is recommended to set the proper construction contents according to the regional features and predominant users. The architecture of the NGSH has to consider its sustainability to guarantee that the proposed smart highway is applicable for different development stages.

(2) The existing NGSH design and construction mainly concentrate on a single scenario and lacks overall consideration. Many projects are designed for a specific objective (i.e., autonomous driving, lifecycle maintenance, and information publication), which leads to the utility of the complete element sensing not being brought into play. It is necessary to fully integrate existing resources to create a synthetical system, which can be utilized for various scenarios.

(3) The construction of the NGSH lacks uniform data specifications and standards, resulting in poor migration and replication of the mature applications. Since the construction of NGSH is still in the exploration stage, there are still large differences in 
TABLE 3: Smart levels of the new generation of smart highway.

\begin{tabular}{|c|c|c|c|c|c|c|c|c|}
\hline \multirow{2}{*}{ Level } & \multirow{2}{*}{$\begin{array}{l}\text { Name } \\
\text { Conventional } \\
\text { highway }\end{array}$} & \multicolumn{4}{|c|}{ Date feature } & \multicolumn{3}{|c|}{ Function features } \\
\hline & & $\begin{array}{l}\text { Permanent } \\
\text { static data }\end{array}$ & $\begin{array}{l}\text { Transient } \\
\text { static data }\end{array}$ & $\begin{array}{c}\text { Transient } \\
\text { dynamic data }\end{array}$ & $\begin{array}{l}\text { Highway } \\
\text { dynamic } \\
\text { data }\end{array}$ & $\begin{array}{l}\text { Information } \\
\text { provision }\end{array}$ & $\begin{array}{l}\text { Perception } \\
\text { enhancement }\end{array}$ & $\begin{array}{c}\text { Cooperation } \\
\text { driving }\end{array}$ \\
\hline R2 & $\begin{array}{c}\text { Preliminary } \\
\text { smart highway }\end{array}$ & & & & & & & \\
\hline R3 & $\begin{array}{l}\text { Partial smart } \\
\text { highway }\end{array}$ & $\bullet$ & $\bullet$ & $\circ$ & & $\bullet$ & $\circ$ & \\
\hline R4 & $\begin{array}{c}\text { Conditional } \\
\text { smart highway }\end{array}$ & $\bullet$ & $\bullet$ & $\bullet$ & $\circ$ & & $\bullet$ & $\bullet$ \\
\hline R5 & $\begin{array}{c}\text { Full smart } \\
\text { highway }\end{array}$ & $\bullet$ & $\bullet$ & $\bullet$ & $\bullet$ & $\bullet$ & $\bullet$ & $\bullet$ \\
\hline Level & Name & \multicolumn{7}{|c|}{ Description } \\
\hline R1 & $\begin{array}{c}\text { Conditional } \\
\text { smart highway }\end{array}$ & \multicolumn{7}{|c|}{ Conventional highway without any digital facilities } \\
\hline R2 & $\begin{array}{c}\text { Preliminary } \\
\text { smart highway }\end{array}$ & \multicolumn{7}{|c|}{$\begin{array}{c}\text { Highway with some precollected static data (road alignment, marks, signs, etc.), which provides basic map } \\
\text { functions. }\end{array}$} \\
\hline R3 & $\begin{array}{l}\text { Partial smart } \\
\text { highway }\end{array}$ & \multicolumn{7}{|c|}{$\begin{array}{l}\text { R2 highway + the ability of collecting the transient static data (pavement performance, maintenance, activities, } \\
\text { etc.) and limited transient dynamic data, which provides some primary environment information for vehicles. }\end{array}$} \\
\hline $\mathrm{R} 4$ & $\begin{array}{l}\text { Conditional } \\
\text { smart highway }\end{array}$ & \multicolumn{7}{|c|}{$\begin{array}{l}\text { R3 highway+the ability of sensing the transient dynamic data (congestion, signal, etc.) and limited highly } \\
\text { dynamic data, which enhances the vehicles perception towards road infrastructures. }\end{array}$} \\
\hline R5 & $\begin{array}{l}\text { Full smart } \\
\text { highway }\end{array}$ & \multicolumn{7}{|c|}{$\begin{array}{l}\text { R4 highway+the ability of sensing the highly dynamic data (trajectory, vehicle movements, etc.) Which provides } \\
\text { complete elements awareness and cooperative driving. R5 highway can control and optimize the traffic flow } \\
\text { from a macro perspective }\end{array}$} \\
\hline
\end{tabular}
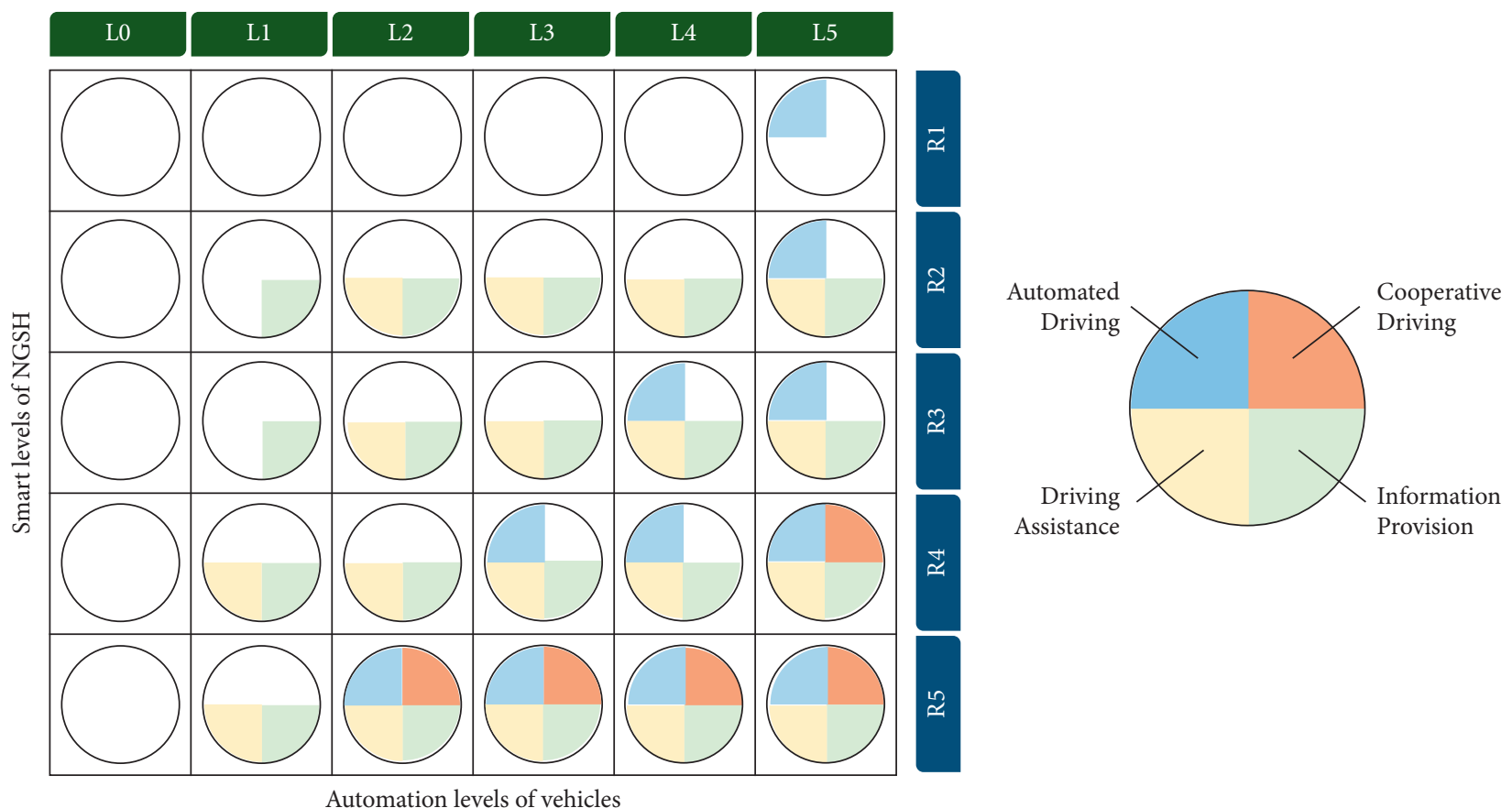

FIgURE 8: Combined effect of vehicle's automated level and highway's smart level.

data types, formats, protocols, and communication methods. Therefore, relevant standards should be set to ensure that the NGSH applications with different architectures can interoperate with each other.
(4) Although current NGSH functions, such as CVIS, over-the-horizon perception, and security enhancement have achieved productive research results, there are certain problems in communication stability, data security, and privacy 


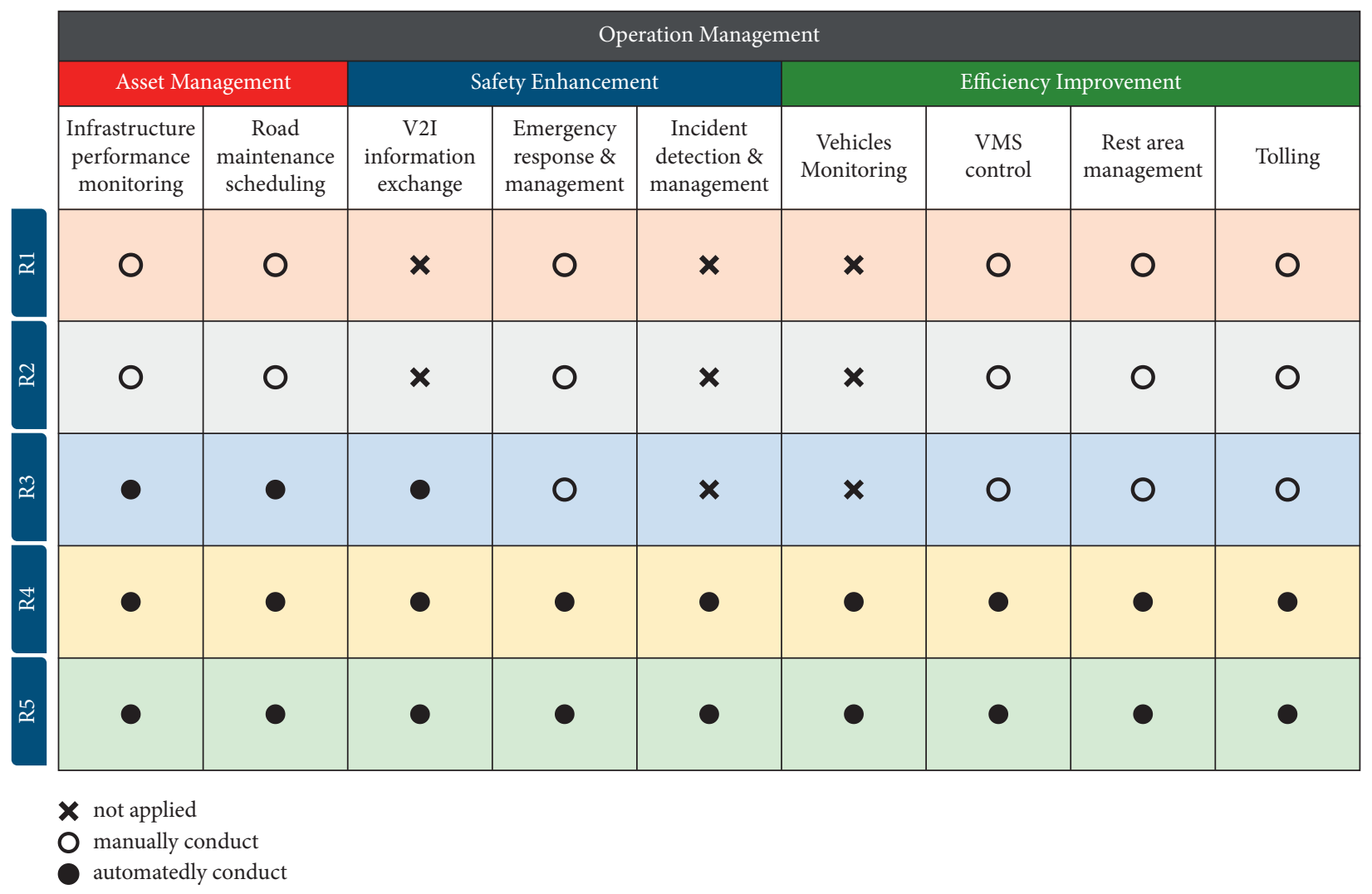

FIGURE 9: Operation management classification under different smart levels of NGSH.

protection, especially for the case of multiterminal interactive environment. Therefore, the study in the next stage needs to improve the robustness of the NGSH to external attacks and protect the privacy of users.

\section{Conclusion}

This paper proposes the framework of the new generation of the smart highway (NGSH), which is a cyber-physical system and integrates various computing, communication, and control technologies. According to the coupling development of road transport and the automotive industry, we summarize the fundamental technical features of the NGSH. The following findings and implications are drawn:

(1) The NGSH consists of four main components: complete element sensing, CPS platform, CVIS applications, and telecommunications. The core feature of NGSH is the interactive collaboration between automated vehicles and smart infrastructure.

(2) The physical architecture of the NGSH defines the basic elements and major components in the NGSH system. The data requirements for different application scenarios have been specified in terms of accuracy, dimension, and freshness.

(3) The smart levels of the NGSH are divided according to the data time-sensitive features and function features. Five smart levels are defined from conventional highway (R1) to full smart highway (R5).

(4) According to the update frequency, the CPS platform is composed of permanent static data (i.e., road geometry, landmarks), transient static data (i.e., road quality, visuality), transient dynamic data (i.e., congestion, weather), and highly dynamic data (i.e., moving vehicles, pedestrians).

(5) The CVIS applications are divided into information provision, perception enhancement, and cooperative driving, which is oriented to vehicles with different automation levels.

(6) The combined effect of the vehicle's automated level and highway's smart level is discussed, which reveals different stages of the NGSH and automated vehicle system. Meanwhile, the key issues in the current stage are illustrated from the perspective of the sustainability and economical applicability of the NGSH.

\section{Data Availability}

All of the data related to this paper are available for peer researchers to validate.

\section{Conflicts of Interest}

The authors declare that there are no conflicts of interest regarding the publication of this paper. 


\section{Acknowledgments}

This study was jointly supported by Scientific Research Project of Shanghai Science and Technology Commission (20DZ2251900, 20DZ1202104, and 21DZ1200601) and National Natural Science Foundation of China (NSFC52108411 and NSFC 52008309). The authors would like to acknowledge the support provided by Jing Cao, Zihang Weng for providing relevant research data.

\section{References}

[1] P. H. Wright and R. J. Paquette, Highway Engineering, John Wiley and Sons Ltd, New York, NY, USA, 2nd edition, 1987.

[2] Y. Gao, J. Wenwen, and H. Chen, "Influence of highway on regional economy: a case from qingdao yinchuan expressway route," in Proceedings of the E3S Web of Conferences, vol. 253, Changsha, China, April 2021.

[3] Y. Yang, Z. Yuan, J. Chen, and M. Guo, "Assessment of osculating value method based on entropy weight to transportation energy conservation and emission reduction," Environmental Engineering \& Management Journal (EEMJ), vol. 16, no. 10, 2017.

[4] Y. Ge, X. Liu, L. Tang, and D. M. West, "Smart transportation in china and the united states," Center for Technology Innovation, Brookings Institution, Washington, DC, USA, 2017.

[5] D. Guo, W. Zhou, A. Sha, and R. Bai, "Application of Uncertainty Analytic Hierarchy Process Method for Asphalt Pavement Construction Quality Control in China," Transportation research record, vol. 2098, no. 1, pp. 43-50, 2009.

[6] R. Whelan, Smart Highways, Smart Cars, Artech House Publishers, Norwood, MA, USA, 1995.

[7] W. B. Stevens, "The automated highway system program: a progress report," IFAC Proceedings Volumes, vol. 29, no. 1, pp. 8180-8188, 1996.

[8] I. L. Al-Qadi, A. Loulizi, M. Elseifi, and S. Lahouar, "The Virginia Smart Road: the impact of pavement instrumentation on understanding pavement performance," Journal of the Association of Asphalt Paving Technologists, vol. 73, no. 3, pp. 427-465, 2004.

[9] A. Pande, Evaluation of Adaptive Ramp Metering on I-80 in the San Francisco Bay Area, The University of Texas at Arlington, Arlington, TX, USA, 2018.

[10] A. Saroj, S. Roy, A. Guin, M. Hunter, and R. Fujimoto, "Smart City Real-Time Data-Driven Transportation Simulation," in Proceedings of the 2018 Winter Simulation Conference (WSC), pp. 857-868, Gothenburg, Sweden, December 2018.

[11] S. An, B.-H. Lee, and D.-R. Shin, "A survey of intelligent transportation systems," in Proceedings of the 2011 Third International Conference on Computational Intelligence, Communication Systems and Networks, pp. 332-337, Bali, Indonesia, July 2011.

[12] A. Fujimoto, S. Koichi, O. Michiya et al., "Toward realization of Smartway in Japan," in Proceedings of the 15th World Congress on Intelligent Transport Systems and ITS America's 2008 Annual Meeting, New York, NY, USA, 2008.

[13] R. Imai, T. Matsushima, and S. Kanai, "Proposal of automatic correction method of incorrect origin-destination in etc 2.0 probe data," Journal of Japan Society of Civil Engineers, Ser. F3 (Civil Engineering Informatics), vol. 74, 2018.

[14] C. Hildebrandt, T. Bandyszak, A. Petrovska, N. Laxman, E. Cioroaica, and S. Törsleff, "EURECA: epistemic uncertainty classification scheme for runtime information exchange in collaborative system groups," SICS Software-Intensive CyberPhysical Systems, vol. 34, no. 4, pp. 177-190, 2019.

[15] F. R. Soriano, V. R. Tomás, and M. Pla-Castells, "Deploying harmonized ITS services in the framework of EasyWay project: traffic Management Plan for corridors and networks," in Proceedings of the in 2012 6th Euro American Conference on Telematics and Information Systems (EATIS), pp. 1-7, Valencia, Spain, May 2012.

[16] T. Victor, M. Rothoff, E. Coelingh, A. Ödblom, and K. Burgdorf, "When autonomous vehicles are introduced on a larger scale in the road transport system: the Drive $\mathrm{Me}$ project," in Automated DrivingSpringer, New York, NY, USA, 2017.

[17] J. Erhart, A. Carreras, X. Daura et al., "Novel approaches for analysing and testing the effect of autonomous vehicles on the traffic flow," in Proceedings of the 26th ITS World Congress (ITSCWC 2019), Singapore, October 2019.

[18] Y. Du, B. Qin, C. Zhao, Y. Zhu, J. Cao, and Y. Ji, “A novel spatio-temporal synchronization method of roadside asynchronous MMW radar-camera for sensor fusion," IEEE Transactions on Intelligent Transportation Systems, 2021.

[19] S. Fu, L. Wenhong, J. Ge, and Y. Qu, "Review on the application of freeway CVIS communication technology," in," MATEC Web of Conferences, vol. 325, p. 01006, 2020.

[20] L. Sun, H. Zhao, H. Tu, and Y. Tian, "The smart road: practice and concept," Engineering, vol. 4, no. 4, pp. 436-437, 2018.

[21] E. H. Wakefield, "History of the electric automobile-hybrid electric vehicles," vol. 187, SAE International, Warrendale, PA, USA, 1998.

[22] H. Niemann, The Mercedes-Benz History: Automobile Legends and Stories since 1886, Mercedes-Benz Classique Car Library, Stuttgart, Germany, 2007.

[23] R. Snedden, Roads, The Rosen Publishing Group, Inc, New York, NY, USA, 2016.

[24] R. P. Roess and E. S. Prassas, The Highway Capacity Manual: A Conceptual and Research History, Springer, New York, NY, USA, 2014.

[25] M. G. Lay, Ways of the World: A History of the World's Roads and of the Vehicles that Used Them, Rutgers university press, New Brunswick, NJ, USA, 1992.

[26] W. K. Kittelson and R. P. Roess, "Highway capacity analysis after highway capacity manual 2000," Transportation Research Record, vol. 1776, no. 1, pp. 10-16, 2001.

[27] L. Zhao and J. Sun, "Simulation framework for vehicle platooning and car-following behaviors under connected-vehicle environment," Procedia-Social and Behavioral Sciences, vol. 96, pp. 914-924, 2013.

[28] S. O.-R. A. D. Committee, "S. A. E. J3016. taxonomy and definitions for terms related to driving automation systems for On-road motor vehicles," Technical Report, SAE International, Warrendale, PA, USA, 2016.

[29] R. Baheti and H. Gill, "Cyber-physical systems," The Impact of Control Technology, vol. 12, no. 1, pp. 161-166, 2011.

[30] M. Batty, Digital Twins, SAGE Publications Sage UK, London, England, 2018.

[31] C.-R. Rad, O. Hancu, I.-A. Takacs, and G. Olteanu, "Smart monitoring of potato crop: a cyber-physical system architecture model in the field of precision agriculture," Agriculture and Agricultural Science Procedia, vol. 6, pp. 73-79, 2015.

[32] N. Al-Falahy and O. Y. Alani, "Technologies for 5G networks: challenges and opportunities," IT Professional, vol. 19, no. 1, pp. 12-20, 2017. 
[33] Y. Yang, Z. Z. Yuan, D. Y. Sun, and X. L. Wen, "Analysis of the factors influencing highway crash risk in different regional types based on improved Apriori algorithm," Advances in Transportation Studies, vol. 49, pp. 165-178, 2019.

[34] A. Carreras, X. Daura, J. Erhart, and S. Ruehrup, "Road infrastructure support levels for automated driving," in Proceedings of the ITS World CongressAt: Copenhagen, EUTP1488, Copenhagen, Denmark, December 2018. 